\title{
Assessment of Self-Piercing Riveted Joints Using the Analytic Hierarchy Process
}

\author{
Ebad Bagherpour * (D), Yan Huang and Zhongyun Fan \\ Brunel Centre for Advanced Solidification Technology, Brunel University London, Uxbridge UB8 3PH, UK \\ * Correspondence: Ebad.Bagherpour@brunel.ac.uk; Tel.: +44(0)1895-266349; Fax: +44(0)1895-269758
}

Received: 6 June 2019; Accepted: 2 July 2019; Published: 6 July 2019

\begin{abstract}
Self-piercing riveting (SPR) as a solid-state joining technology has recently found extensive applications in the automotive industry, mostly in the joining of car body aluminium sheets. To achieve an acceptable joint, key operation and tooling parameters, including set force, die profile, and rivet shape and hardness, should be selected appropriately. To evaluate joint performance, the interlocking parameters and joint strength have to be determined. In the current laboratory and industrial practices, joint quality is assessed according to requirements of individual applications, lacking a systematic assessment method. The goal of the present study is to develop a method to determine the SPR conditions that produce a joint of the best quality, based on an analytic hierarchy process (AHP), which is a methodology for relative measurement. A general AHP model was proposed for analysing SPR and joint performance in different conditions and with an unlimited number of criteria and alternatives. Joints of two layers of $2.5 \mathrm{~mm}$ thick AA6082 aluminium sheets in T6 condition were produced using various dies, rivets, and SPR processing conditions. A selection of seven joints, which achieved minimum requirements in terms of interlocking parameters and strength, was nominated for AHP assessment. With the application of six criteria, including head height, bottom thickness, minimum bottom thickness, deformed rivet diameter, shear strength, and peel strength, the AHP assessment was able to define the best conditions for the SPR joining of the aluminium alloy sheets.
\end{abstract}

Keywords: self-piercing riveting (SPR); analytic hierarchy process (AHP); car body aluminium sheets; materials selection

\section{Introduction}

In spite of the long history of riveting in metal joining, going back to the Bronze Age, its applications have been limited by the availability of weldable metals and feasible rivet materials for less expensive and easy automation welding techniques [1]. Self-piercing riveting (SPR) as a development of riveting process started to find its way in industrial applications since 1975, due to its unique features [2]. Compared with the traditional joining methods, SPR has the following advantages [2]:

(1) Less environmental pollution;

(2) Can be used to join both similar and dissimilar materials;

(3) No need for pre-drilling or punching holes;

(4) No prerequisite for surface pre-treatment;

(5) Capability to use lubricants and adhesives;

(6) High speed production rate;

(7) Long tool life;

(8) High static and fatigue joint strengths;

(9) Ability to automate and monitor the process easily. 
The SPR process is used to join two or more similar or dissimilar sheet materials by driving a rivet through the top sheet and partially to the bottom sheet. The process creates an interlock between the sheets by flaring the rivet skirt, directed by a suitable die, without piercing through the bottom sheet $[2,3]$. SPR is a cold process, and unlike the conventional riveting process, does not require a pre-drilled hole, therefore possessing the same joining speed as that of the resistance spot welding [4]. As shown in Figure 1a, the performance of an SPR process depends on several parameters, including the stack thickness, set force, die shape, die geometry, and the geometry, shape, and hardness of the rivet [2]. The primary parameter regarding the joint quality is the joint interlock, which can be defined by sectioning the joint. A schematic diagram of a joint section is illustrated in Figure $1 \mathrm{~b}$. While deformed rivet diameter $\left(D_{d r}\right)$ and rivet flaring $(X)$ represent the interlocking, bottom thickness $\left(t_{b}\right)$ and minimum bottom thickness $\left(t_{b_{\min }}\right)$ have a strong effect on the strength of the joint. The procedure that is used by the automotive industry to evaluate the quality of an SPR joint involves measurement of the rivet head height $(h)$ above (or below) the surface of the top sheet and the rivet flaring $(X)[5,6]$. Preferably, $h$ should be around zero $( \pm 0.05 \mathrm{~mm})$, and as long as no crack appears in the rivet, the greater the interlock distance leads to the better quality of the joints. After achieving a satisfactory joint structure, joint strength is typically evaluated by shear and peel tests.

The assessment of a joint requires examination and test of a range of parameters and properties, including interlock, sufficient $t_{b}$ and $t_{b_{\text {min }}}$, around-zero $h$, and high peel and shear strength. Therefore, comparing joints, ranking them, and choosing the best joint are critically important in determining the best conditions for SPR processing. Generally, these steps are significant in most material and process selection problems [7,8]. In the case of SPR in which a large number of selection criteria are involved, a simple and systematic method for joint analysis and process optimization is needed. For a specified engineering module dependent on several criteria, the proposed multi-criteria decision making (MCDM) [9] approach is a powerful tool to rank the alternatives. Simply, in the selection procedure, the multi-criteria decision making (MCDM) methods have been used commonly for the properties that can be represented by numerical values [10]. In 1990, Saaty [11] introduced a new method of MCDM named the Analytic Hierarchy Process (AHP), which has been frequently used by decision makers facing a complex problem with multiple conflicting and subjective criteria due to its high merit and its simplicity. AHP has several applications in different scientific, management, and manufacturing fields [12]. Despite the high potential of the AHP in both materials selection and process optimization, there are few reports considering AHP in this field. Bagherpour et al. [10] applied this method to select the best $\mathrm{Al} / \mathrm{SiC}$ composite to satisfy the best combination of strength and workability. The AHP method was utilized in the selection of the most suitable natural fiber to be hybridized with glass-fiber-reinforced polymer composites for the design of a passenger vehicle center lever parking brake component in 2013 by Mansor et al. [13]. The application of AHP to minimize environmental impact in screw manufacturing [14] is a good example for the use of AHP in process optimization. One of the interesting usages of AHP in this field was reported in 2018 [15], where this method was used to determine the best choice of 3D scanner for cultural heritage applications. In some studies, AHP has been used in combination with other selection methods for the more complicated problems [16].

In the present study, a systematic assessment model based on the AHP method is proposed to determine the optimal conditions for obtaining SPR joints of the best quality. 


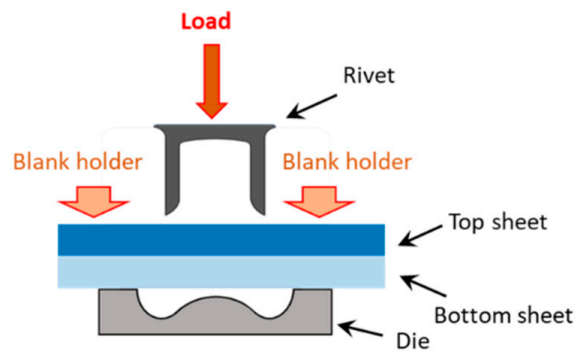

(a)

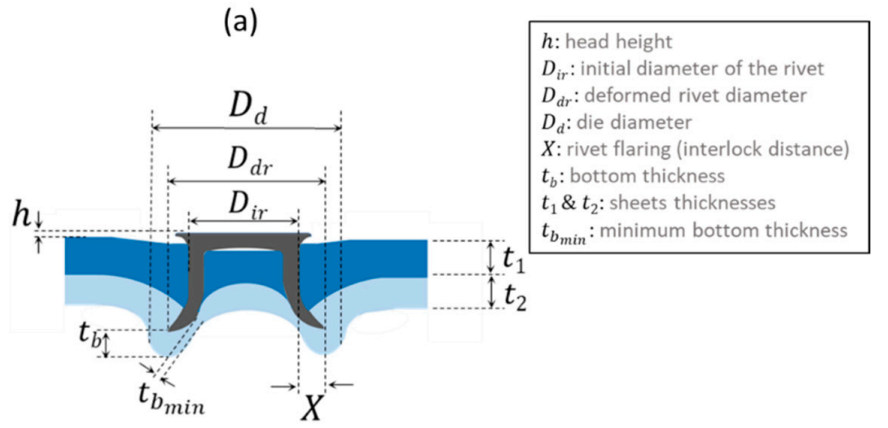

(b)

Figure 1. Schematic representation of a self-piercing riveting (SPR) joint: (a) the stack of the process; (b) different parameters of the joint.

\section{Theoretical Basis of the AHP}

In a general sense, AHP is a methodology for "relative measurement" [12]. The use of pair-wise comparisons between the quantities instead of direct allocation of their weights is the essence of the relative measurement and of AHP as well [17]. AHP is based on three steps: problem modelling, comparative judgment of alternatives and criteria, and synthesis of priorities $[12,17,18]$. In materials science, different experimental situations and corresponding samples are considered as alternatives. In addition, each of the calculated and measured properties could be a criterion. In other words, the aim of an AHP model in the selection of the materials or methods is to find the best state of experiments in order to have the best combination of multiple properties $[10,15,16,19]$. It should be noted that each of the considered properties must necessarily be independent [10].

\subsection{Problem Modelling}

To facilitate a complex decision problem, AHP has the advantage of permitting a structure of criteria as a hierarchy. At first, AHP overwhelms a complex multi-criteria decision-making problem into a hierarchy of interconnected decision elements, such as criteria (properties), decisions, and alternatives (samples, methods, and experimental conditions). The hierarchical structure of objectives, criteria, and alternatives produced in this step, similar to a family tree, provides the decision makers a better focus on criteria and sub-criteria when assigning the weights. A hierarchy is compounded by a goal, a set of alternatives $\left(X=\left\{x_{1}, x_{2}, \ldots, x_{m}\right\}\right)$, a set of criteria, and a relation to the goal, the criteria, and the alternatives [11,12].

\subsection{Pair-Wise Comparisons and Judgement Scales}

After the decomposition of the problem and the construction of the hierarchy, prioritization starts with the purpose of determining the relative importance of the criteria at each level. The pair-wise judgment starts from the second level and finishes at the lowermost level. The criteria are compared pairwise at each level according to their altitudes and based on the specified criteria at the higher level. A decision maker does not need to deliver a numerical judgement; as an alternative, a relative verbal appreciation that is more acquainted to everyday lives is satisfactory [17]. Therefore, the decision 
maker can declare opinions on pairs using linguistic terms associated with real numbers. In Saaty's scale $[11,12]$, the verbal statements are converted into integers from one to nine. Table 1 displays the match of Saaty's scale to verbal judgments used in the weighting of two elements.

Table 1. Pair comparison evaluation scale (Saaty's scale) [11,12].

\begin{tabular}{cc}
\hline Relative Importance $\left(a_{i j}\right)$ & Description $(i$ over $j)$ \\
\hline 1 & Equal importance \\
2 & Weak \\
3 & Moderate importance \\
4 & Moderate plus \\
5 & Strong importance \\
6 & Strong plus \\
7 & Very strong importance \\
8 & Very, very strong \\
9 & Absolute importance \\
\hline
\end{tabular}

The pair-wise comparisons of alternatives for each of the priorities $\left(p_{1}, p_{2}, \ldots, p_{n}\right)$ are recorded in positive reciprocal matrices:

$$
A^{p_{i}}=\left[\begin{array}{cccc}
1 & a_{12} & \ldots & a_{1 m} \\
a_{21} & 1 & \ldots & a_{2 m} \\
\vdots & \vdots & \vdots & \vdots \\
a_{n m 1} & a_{m 2} & \ldots & 1
\end{array}\right]
$$

where $a_{i j}$ is the comparison between elements $i$ and $j$, and $m$ is the number of alternatives involved in the evaluation.

According to Saaty's theory, each entry of Matrix $A$ (Equation (1)) is supposed to be the ratio between two quantities:

$$
a_{i j}=\frac{w_{i}}{w_{j}} \forall i, j
$$

Considering Equation (1), the condition of multiplicative reciprocity is satisfied as:

$$
a_{i j}=\frac{1}{a_{j i}} \forall i, j
$$

Inserting Equation (3) into Matrix $A^{p_{i}}(1)$ :

$$
A^{p_{i}}=\left[\begin{array}{cccc}
1 & a_{12} & \ldots & a_{1 m} \\
\frac{1}{a_{1 m}} & 1 & \ldots & a_{2 m} \\
\vdots & \vdots & \vdots & \vdots \\
\frac{1}{a_{1 m}} & \frac{1}{a_{2 m}} & \ldots & 1
\end{array}\right]
$$

Therefore, the number of performed pair-wise comparisons is $\frac{m(m-1)}{2}$ [20].

Once a pairwise comparison matrix for a priority is completed, there are several ways to derive the priority vector $w^{p_{i}}\left(w^{p_{i}}=\left\{w_{1}^{p_{i}}, w_{2}^{p_{i}}, \ldots, w_{m}^{p_{i}}\right\}^{T}\right)$, such as eigenvector [11,18] and geometric mean [21] methods. In the current study we use the geometric mean method due to three main reasons. Firstly, the method can avoid the "rank reversal" problem for scale inversion associated with the eigenvalue method [17]. Generally, the rank reversal can be expressed by changing the priorities by adding a new alternative. Further discussions about the "rank reversal" problem are beyond the scope of this paper and readers are referred to references [12,21] for more information. Secondly, contrary to the eigenvector method, weights can be expressed as analytic functions of the entries of the matrix in this approach [12]. Thirdly, the final weights achieved from the whole hierarchy can be uttered as analytic 
expressions of the entries of all the matrices involving in the hierarchy. According to this method each component of $w^{p_{i}}$ is obtained by:

$$
\boldsymbol{w}^{p_{i}}=\frac{\sqrt[m]{\prod_{j=1}^{m} a_{i j}}}{\sum_{i=1}^{m} \sqrt[m]{\prod_{j=1}^{m} m_{i j}}}
$$

To complete the analysis, the described procedure is repeated for all subsystems in the hierarchy. In order to synthesize the various priority vectors, these vectors are weighted with the global priority of the parent criteria and synthesized. Therefore, each of the priority vectors make one of the columns in the total pairwise comparison matrix $\left(A_{m \times n}\right)$ :

$$
\boldsymbol{A}=\left[\begin{array}{cccc}
w_{1}^{p_{1}} & w_{1}^{p_{2}} & \ldots & w_{1_{n}}^{p_{n}} \\
w_{2}^{p_{1}} & w_{2}^{p_{2}} & \ldots & w_{2}^{p_{n}} \\
\vdots & \vdots & \vdots & \vdots \\
w_{m}^{p_{1}} & w_{m}^{p_{2}} & \ldots & w_{m}^{p_{n}}
\end{array}\right]
$$

\subsection{Consistency}

Priorities are acceptable only if obtained from consistent or near consistent matrices. Therefore, the last step in the AHP is the consistency check. For a perfectly consistent matrix, the transitivity rule is essential for all comparisons [17,18]:

$$
a_{i j}=a_{i k} \cdot a_{j k} \forall i, j, k
$$

Inconsistency can occur in the formation of $A$. Inconsistency happens when the priority (property) has a qualitative nature and cannot be quantified. In this case, components of $A$ are defined using Saaty's scale (Table 1). Because weighting using Saaty's scale is made independently, the transitivity rule is not necessarily satisfied. In other words, if all the priorities are quantities, then all of the $A^{p_{i}}$ will be completely consistent. Otherwise, $A$ must be checked to satisfy the consistency.

Among several methods proposed to check the consistency (for more detail please refer to references [9,12,17]), the Consistency Index (CI) [22] and Geometric Consistency Index (GCI) [23] have attracted more attention. In spite of its high popularity, the CI has been criticised due to the permission of inconsistent matrices [24] or rejection of rational matrices [25]. Therefore, GCI was selected for the consistency check in this research. GCI is defined as [26]:

$$
G C I(A)=\frac{2}{(n-1)(n-2)} \sum_{i<j} \log ^{2} e_{i j}
$$

where $e_{i j}=a_{i j} w_{j} / w_{i}$. Once GCI is calculated, the consistency index can be calculated using [26]:

$$
C R=\frac{G C I}{k(n)}
$$

where $k(n)$ is a parameter depending on $\mathrm{n}$ and can be found in Table 2. According to AHP, the consistency is acceptable as long as $C R$ is less than $0.1(C R=10 \%)$. To satisfy this condition, GCI should be less than 0.3147 for $n=3,0.3256$ for $n=4$, and 0.370 for $n>4$ [17].

Table 2. Values of $k(n)$ for $n=3, \ldots, 16$ [26].

\begin{tabular}{ccccccccccccccc}
\hline$n$ & $\mathbf{3}$ & $\mathbf{4}$ & $\mathbf{5}$ & $\mathbf{6}$ & $\mathbf{7}$ & $\mathbf{8}$ & $\mathbf{9}$ & $\mathbf{1 0}$ & $\mathbf{1 1}$ & $\mathbf{1 2}$ & $\mathbf{1 3}$ & $\mathbf{1 4}$ & $\mathbf{1 5}$ & $\mathbf{1 6}$ \\
\hline$k(n)$ & 3.147 & 3.526 & 3.717 & 3.755 & 3.755 & 3.744 & 3.733 & 3.709 & 3.698 & 3.685 & 3.674 & 3.663 & 3.646 & 3.646 \\
\hline
\end{tabular}




\section{Experiments}

\subsection{Experimental Procedure}

Extensive SPR experiments were performed in order to obtain the required data for AHP modelling. AA6082 aluminium coupons in T6 condition with the dimensions of $40 \times 40 \times 2.5 \mathrm{~mm}^{3}$ and of $120 \times 40 \times 2.5 \mathrm{~mm}^{3}$ were used for the SPR processing. Two layers of the AA6082 sheets were joined together in the center with one rivet. The joined samples with the dimensions of $120 \times 40 \times 2.5 \mathrm{~mm}^{3}$ were machined for peel strength and shear strength tests. For SPR joints of different geometries, three jigs were designed and constructed to ensure that the same riveting position was applied for different strength testing conditions. The schematic diagrams of the jigs and the position of the sheets on the stacks are shown in Figure 2. These jigs provide repeatability and accuracy of the joint for strength tests. As seen, after placing the jig in the appropriate position over the die, the sheet stack are placed on the jig and then the riveting process can be started. The mechanical tests were carried out on an INSTRON 3367 universal testing machine with a capacity of $50 \mathrm{KN}$ with $0.1 \mathrm{~mm} / \mathrm{s}$ displacement speed. Three samples were prepared for every joint condition and test.

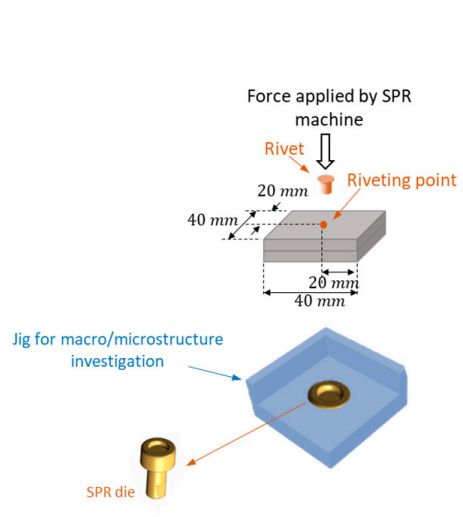

(a)

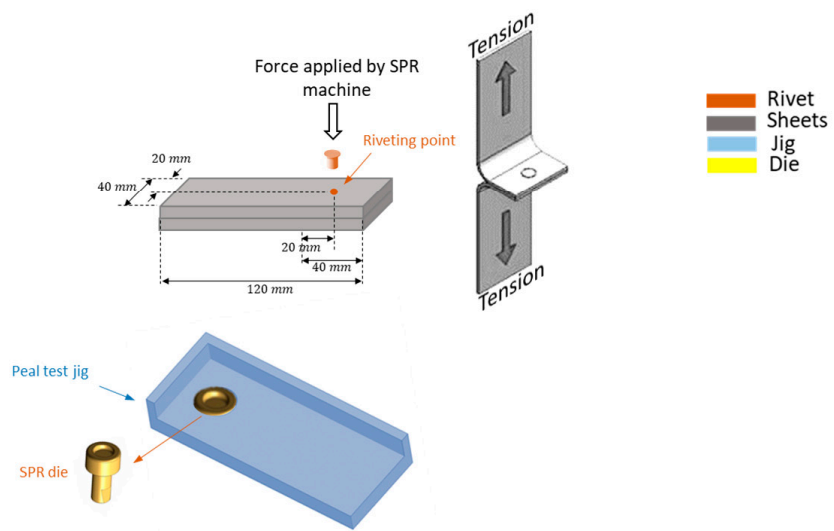

(c)

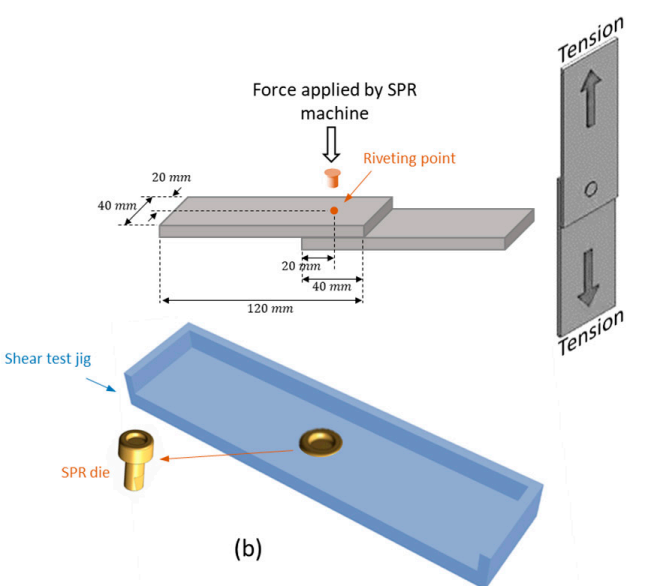

Figure 2. Schematic representation of the jigs and the stacks used to join AA6082-T6 sheets using SPR for (a) macro- and micro-structure investigation, (b) shear strength, and (c) peel strength tests of the joints.

SPR experiments were performed on a Henrob servo-electric SPR machine using $\phi 5.3 \mathrm{~mm}$ (nominal $\phi 5 \mathrm{~mm}$ ) rivets of various configurations. This machine works by storing kinetic energy in a rotating mass (maximum advance velocity of $380 \mathrm{~mm} / \mathrm{s}$ ), which sets the rivet into the joint stack with the help of a linear roller screw. There is no force control in the process. The velocity of the rotating mass is the main controlling condition and the riveting force is determined by the velocity together 
with the other SPR conditions, such as the material to be joined and the workpiece stack, the die, and the rivet. Therefore, the velocity of the rotating mass was the main operation parameter and a range of velocities were applied to examine their impact on the SPR performance. Stainless steel rivets of a mechanically plated alloy of zinc and tin (H00 serious of Henrob products) $5.3 \mathrm{~mm}$ (nominal $5 \mathrm{~mm}$ ) in diameter and $6.5,7,7.5$, and $8 \mathrm{~mm}$ in length were used in this study. The shape of the rivets is flared-hole semi-tubular. The hardness of the rivets varied from 420 to $460 \mathrm{Hv}$. Flat bottomed dies with diameters of 9.0 and $10.0 \mathrm{~mm}$ and various depths of 1.2,1.4,1.6, and $1.8 \mathrm{~mm}$ were employed.

\subsection{Experimental Results}

As described in the previous section, different joining conditions were tested to achieve an acceptable joint. Among trials of more than 40 combinations of conditions, only a limited number of them achieved the requirements of a good quality joint. There are several reasons responsible for the failure of joints, including the following:

(1) Insufficient interlock;

(2) The rivet tip breaking through into the die;

(3) Rivet collapsing;

(4) Under- or over-flashing of the head;

(5) Excessive flaring;

(6) Leg or tip tearing;

(7) Formation of circumferential cracks;

(8) Asymmetric deformation of the rivet;

(9) Formation of bottom cracks.

Examinations of the failed joints as illustrated in Figure 3 revealed that there were a few reasons responsible for the failure of joints, such as surface cracks on the bottom sheet, under- or over-flashing of the head, over-flow of the rivet (Excessive flaring), and asymmetrically deformed rivets, resulting in low shear and peel strength. Figure 4 shows the crack formation in the joint when over-flow of the rivet happens. When the rivet flared excessively, the material around the flared rivet, either in the outer or inner regions of the rivet tail in the top sheet suffered high tensile stress, which is considered to be the main cause of crack initiation and propagation. The joints that passed the initial quality check were selected for assessment by the AHP model. Figure 5 shows a cross-section of an accepted joint, which is free from cracks in the bottom sheet. Besides, all the interlocking parameters $\left(h, t_{b}, t_{b_{\text {min }}}\right.$, and $\left.D_{\mathrm{dr}}\right)$ are in acceptable ranges. A summary of the SPR conditions for the accepted joints is presented in Table 3.

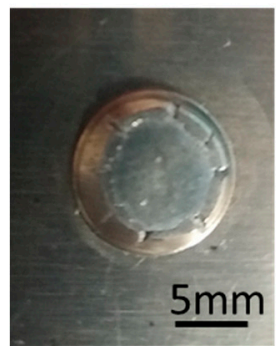

(a)

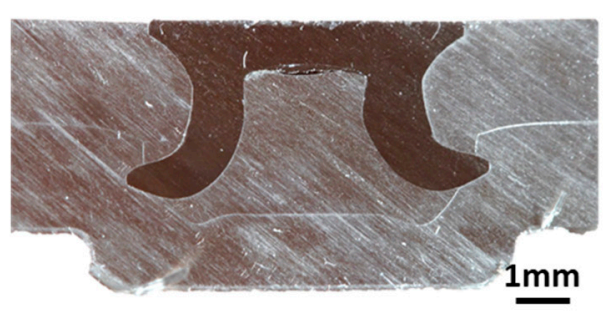

(b)

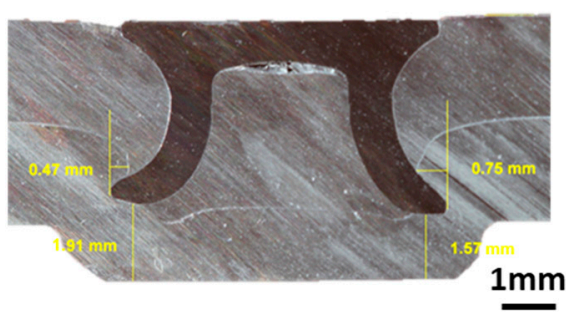

(c)

Figure 3. Different failed joints that could not fulfill the requirements of an acceptable joint: (a) surface cracks on the bottom joint performed using $\phi 9 \mathrm{~mm}$ die with a depth of $1.8 \mathrm{~mm}$ and a rivet with a length of $7 \mathrm{~mm}$ and hardness of $420 \mathrm{Hv}$ with a velocity of $270 \mathrm{~mm} / \mathrm{s}$; (b) over-flowing of the rivet (large deformed rivet diameter) of a joint using $\phi 10 \mathrm{~mm}$ die with the depth of $1.2 \mathrm{~mm}$ and a rivet with a length of $7 \mathrm{~mm}$ and hardness of $420 \mathrm{Hv}$ with a velocity of $360 \mathrm{~mm} / \mathrm{s}$; (c) asymmetrically deformed rivet appearing after a joint using $\phi 10 \mathrm{~mm}$ die with a depth of $1.4 \mathrm{~mm}$ and a rivet with a length of $6.5 \mathrm{~mm}$ and hardness of $440 \mathrm{Hv}$ with a velocity of $350 \mathrm{~mm} / \mathrm{s}$. 


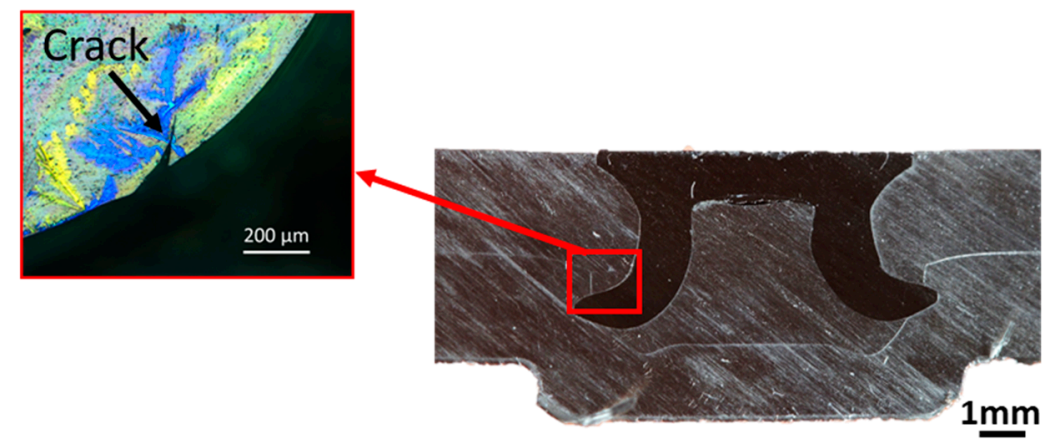

Figure 4. Crack appearing in an upper sheet of a SPR joint with a highly flared (over-flow) rivet. This joint was achieved using $\phi 10 \mathrm{~mm}$ die with a depth of $1.2 \mathrm{~mm}$ and a rivet with a length of $7 \mathrm{~mm}$ and hardness of $420 \mathrm{Hv}$ with a velocity of $360 \mathrm{~mm} / \mathrm{s}$.

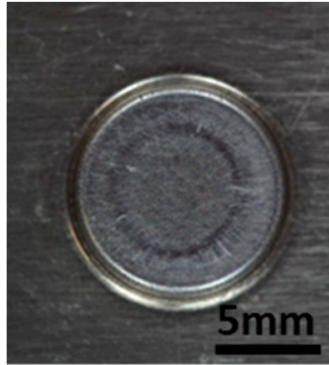

(a)

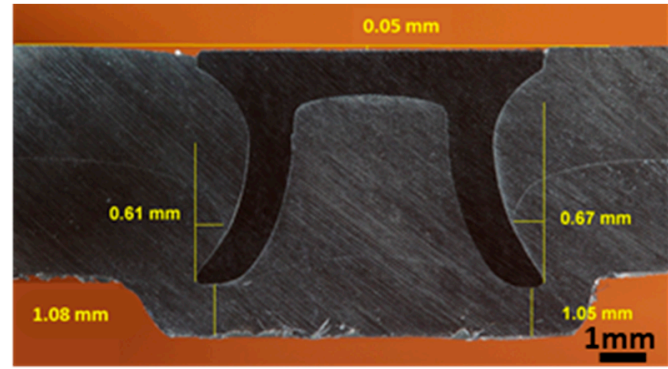

(b)

Figure 5. An acceptable joint made using a die with a diameter of $10 \mathrm{~mm}$ and depth of $1.4 \mathrm{~mm}$, and a rivet with a length of $6.5 \mathrm{~mm}$ and hardness of $460 \mathrm{Hv}$ with a velocity of $345 \mathrm{~mm} / \mathrm{s}$. (a) The surface quality of the riveting point in the bottom sheet, and (b) the cross section of the joint.

To evaluate the strength of the joint, acceptable joints were examined by shear and peel tests. Figure 6 shows the results of these tests. Interestingly for all of the samples, the failure mode of the joints is the rivet pull-out from the bottom sheet (see inset images in Figure 6). The detailed results are given in Table 4 . The data reported in this table are average values alongside the variance. It can be seen from Figure 6 and Table 4 that the highest shear $(11.21 \mathrm{kN})$ and peel strengths $(3.1 \mathrm{kN})$ correspond to $J_{5}$ and $J_{3}$ joints, respectively. The interlocking parameters and joint strengths (in Table 3 ) summarized in Table 4 are used for AHP analysis.

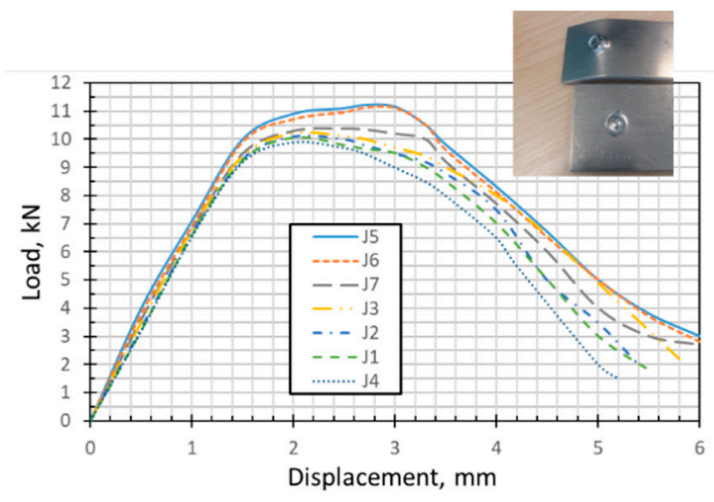

(a)

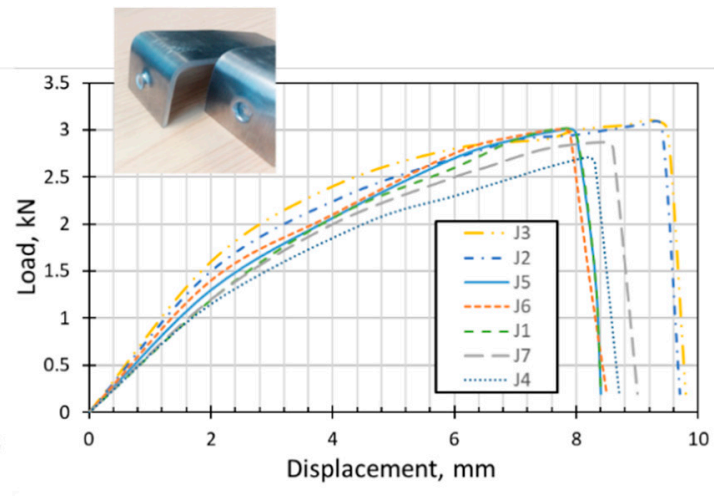

(b)

Figure 6. Representative experimental force-displacement curves for (a) the shear, and (b) peel tests of different joints. 
Table 3. SPR parameters for the acceptable joints.

\begin{tabular}{|c|c|c|c|c|c|c|c|c|c|}
\hline Joint & Die Type & $\begin{array}{c}\text { Die } \\
\text { Diameter, } \\
\text { mm }\end{array}$ & $\begin{array}{c}\text { Die } \\
\text { Depth, } \\
\text { mm }\end{array}$ & Rivet Type & $\begin{array}{c}\text { Rivet } \\
\text { Diameter, } \\
\text { mm }\end{array}$ & $\begin{array}{c}\text { Rivet } \\
\text { Length, } \\
\text { mm }\end{array}$ & $\begin{array}{c}\text { Rivet } \\
\text { Hardness, } \\
\text { Hv }\end{array}$ & $\begin{array}{l}\text { Velocity, } \\
\mathrm{mm} / \mathrm{s}\end{array}$ & $\begin{array}{c}\text { Force, } \\
\text { Kgf }\end{array}$ \\
\hline $\mathrm{J}_{1}$ & $\begin{array}{c}\text { Flat } \\
\text { bottomed die }\end{array}$ & 10 & 1.2 & $\begin{array}{l}\text { flared hole- } \\
\text { semi tubular }\end{array}$ & 5 & 7 & 420 & 360 & 82.8 \\
\hline $\mathrm{J}_{2}$ & $\begin{array}{c}\text { Flat } \\
\text { bottomed die }\end{array}$ & 10 & 1.4 & $\begin{array}{l}\text { flared hole- } \\
\text { semi tubular }\end{array}$ & 5 & 8 & 440 & 360 & 82.4 \\
\hline $\mathrm{J}_{3}$ & $\begin{array}{c}\text { Flat } \\
\text { bottomed die }\end{array}$ & 10 & 1.4 & $\begin{array}{l}\text { flared hole- } \\
\text { semi tubular }\end{array}$ & 5 & 6.5 & 440 & 360 & 85.4 \\
\hline $\mathrm{J}_{4}$ & $\begin{array}{c}\text { Flat } \\
\text { bottomed die }\end{array}$ & 10 & 1.4 & $\begin{array}{l}\text { flared hole- } \\
\text { semi tubular }\end{array}$ & 5 & 6.5 & 440 & 340 & 77 \\
\hline $\mathrm{J}_{5}$ & $\begin{array}{c}\text { Flat } \\
\text { bottomed die }\end{array}$ & 10 & 1.4 & $\begin{array}{l}\text { flared hole- } \\
\text { semi tubular }\end{array}$ & 5 & 6.5 & 460 & 350 & 82.6 \\
\hline $\mathrm{J}_{6}$ & $\begin{array}{c}\text { Flat } \\
\text { bottomed die }\end{array}$ & 10 & 1.4 & $\begin{array}{l}\text { flared hole- } \\
\text { semi tubular }\end{array}$ & 5 & 6.5 & 460 & 345 & 80.7 \\
\hline $\mathrm{J}_{7}$ & $\begin{array}{l}\text { Flat } \\
\text { bottomed die }\end{array}$ & 10 & 1.4 & $\begin{array}{l}\text { flared hole- } \\
\text { semi tubular }\end{array}$ & 5 & 6.5 & 460 & 340 & 78.9 \\
\hline
\end{tabular}

Table 4. SPR joint specifications, including interlocking parameters and strengths.

\begin{tabular}{ccccccc}
\hline Joint & $\begin{array}{c}\text { Head } \\
\text { Height }(\boldsymbol{h}), \\
\mathbf{m m}\end{array}$ & $\begin{array}{c}\text { Bottom } \\
\text { Thickness } \\
\left(\boldsymbol{t}_{\boldsymbol{b}}\right), \mathbf{m m}\end{array}$ & $\begin{array}{c}\text { Minimum } \\
\text { Bottom } \\
\text { Thickness } \\
\left(\boldsymbol{t}_{\left.\boldsymbol{b}_{\text {min }}\right)}\right.\end{array}$ & $\begin{array}{c}\text { Deformed } \\
\text { Rivet } \\
\text { Diameter } \\
\left(\boldsymbol{D}_{\boldsymbol{d} \boldsymbol{r}}\right), \mathbf{m m}\end{array}$ & $\begin{array}{c}\text { Shear } \\
\text { Strength } \\
\left(\boldsymbol{F}_{\boldsymbol{s}}\right), \mathbf{k N}\end{array}$ & $\begin{array}{c}\text { Peel } \\
\text { Strength } \\
\left(\boldsymbol{F}_{\boldsymbol{p}}\right), \mathbf{k N}\end{array}$ \\
\hline $\mathrm{J}_{1}$ & $0.05 \pm 0.01$ & $1.42 \pm 0.1$ & $1.1 \pm 0.1$ & $6.3 \pm 0.1$ & $8.78 \pm 0.15$ & $3.01 \pm 0.03$ \\
$\mathrm{~J}_{2}$ & $0.1 \pm 0.02$ & $1.33 \pm 0.16$ & $1.02 \pm 0.08$ & $6.4 \pm 0.1$ & $9.04 \pm 0.13$ & $3.06 \pm 0.04$ \\
$\mathrm{~J}_{3}$ & $0.06 \pm 0.01$ & $1.53 \pm 0.12$ & $1.08 \pm 0.11$ & $6.35 \pm 0.11$ & $9.54 \pm 0.2$ & $3.1 \pm 0.06$ \\
$\mathrm{~J}_{4}$ & $0.11 \pm 0.02$ & $1.73 \pm 0.18$ & $1.23 \pm 0.15$ & $6.32 \pm 0.1$ & $8.68 \pm 0.16$ & $2.71 \pm 0.05$ \\
$\mathrm{~J}_{5}$ & $0.04 \pm 0.01$ & $1.1 \pm 0.04$ & $0.82 \pm 0.1$ & $6.3 \pm 0.1$ & $11.21 \pm 0.1$ & $3.01 \pm 0.04$ \\
$\mathrm{~J}_{6}$ & $0.06 \pm 0.01$ & $1.28 \pm 0.06$ & $0.96 \pm 0.12$ & $6.25 \pm 0.1$ & $11.11 \pm 0.09$ & $3.01 \pm 0.03$ \\
$\mathrm{~J}_{7}$ & $0.07 \pm 0.01$ & $1.32 \pm 0.07$ & $1.02 \pm 0.1$ & $6.22 \pm 0.1$ & $10.38 \pm 0.12$ & $2.87 \pm 0.05$ \\
\hline
\end{tabular}

\section{SPR Joint Assessment Using AHP}

\subsection{Problem Modelling, Pair-Wise Comparison, Priority Derivation, and Consistency Evaluation}

The aim of this work is to select a joint having the best combination of interlocking, head height, and strength. To achieve this goal, six criteria $(n=6)$, including rivet's head height $(h)$, bottom thickness $\left(t_{b}\right)$, minimum bottom thickness $\left(t_{b_{\text {min }}}\right)$, deformed rivet diameter $\left(D_{d r}\right)$, shear strength $\left(F_{s}\right)$, and peel strength $\left(F_{p}\right)$, were taken into account. Therefore, the decision hierarchy structure for selecting a joint with the declared criteria among $m\left(J_{1}, J_{2}, \ldots, J_{m}\right)$ number of the joints is the one shown in Figure 7. For all criteria, except the head height, a higher amount means better quality. In the case of head height, it is important that the head has good contact with the top sheet, as moisture can gather and cause corrosion issues, which means the ideal head height is zero. Also, it is possible to have a head height with an amount of less than zero, which is evident when the rivet is beneath the sheet's surface. Therefore, Equation (2) cannot be applied for evaluation. To overcome this problem, a reference head height, $h_{0}$, is introduced as the goal for the criteria. Hence, the target for a joint is to have a relative height, $\left|\frac{h_{0}}{h_{i}}\right|$, close to 1 . The absolute value is used to fit the AHP model requirement, although $h_{i}$ can be negative in practice. In this case, using Equation (2), the entries of the pair-wise comparison matrix for the head height $\left(A^{(h)}\right)$ are:

$$
a_{i j}=\frac{h_{j}}{h_{i}} \forall i, j
$$




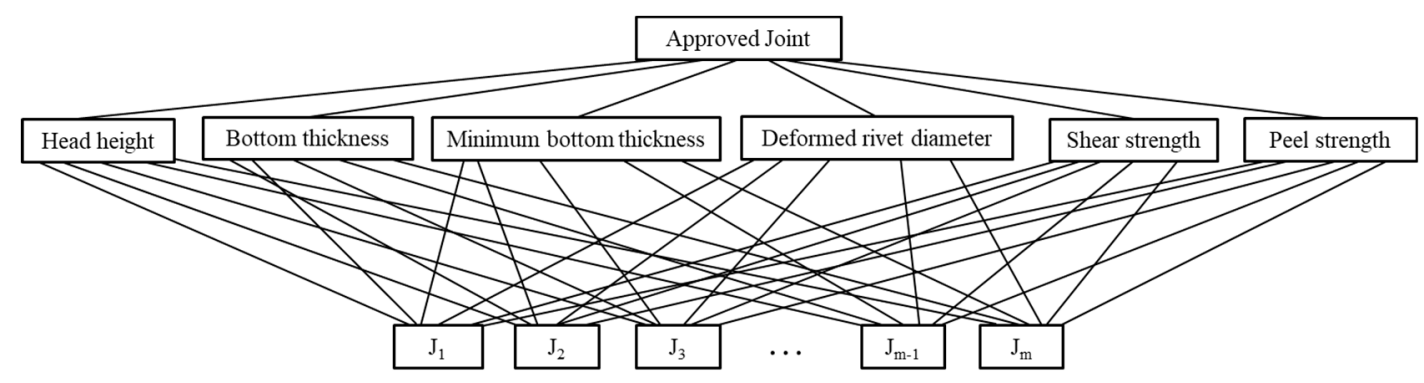

Figure 7. Decision hierarchy structure.

From Equations (3) and (10), the pair-wise comparison matrices for each of the criteria are as below:

$$
\begin{aligned}
& \boldsymbol{A}^{(\boldsymbol{h})}=\left[\begin{array}{cccc}
h_{1} / h_{1} & h_{2} / h_{1} & \ldots & h_{m} / h_{1} \\
h_{1} / h_{2} & h_{2} / h_{2} & \ldots & h_{m} / h_{2} \\
\vdots & \vdots & \vdots & \vdots \\
h_{1} / h_{m} & h_{2} / h_{m} & \ldots & h_{m} / h_{m}
\end{array}\right] \\
& A^{\left(t_{b}\right)}=\left[\begin{array}{cccc}
t_{b 1} / t_{b 1} & t_{b 1} / t_{b 2} & \ldots & t_{b 1} / t_{b m} \\
t_{b 2} / t_{b 1} & t_{b 2} / t_{b 2} & \ldots & t_{b 2} / t_{b m} \\
\vdots & \vdots & \vdots & \vdots \\
t_{b m} / t_{b 1} & t_{b m} / t_{b 2} & \ldots & t_{b m} / t_{b m}
\end{array}\right]
\end{aligned}
$$

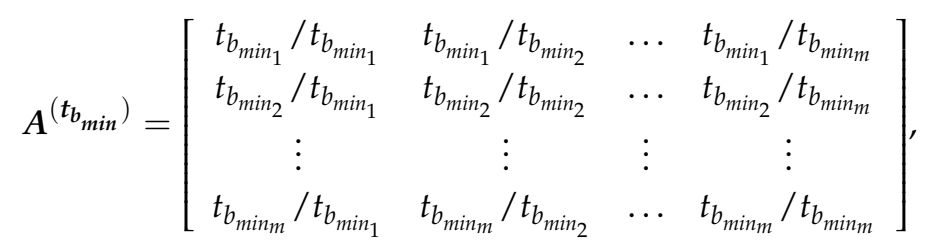

$$
\begin{aligned}
& \boldsymbol{A}^{\left(\boldsymbol{D}_{d r}\right)}=\left[\begin{array}{cccc}
D_{d r 1} / D_{d r 1} & D_{d r 1} / D_{d r 2} & \ldots & D_{d r 1} / D_{d r m} \\
D_{d r 2} / D_{d r 1} & D_{d r}^{2} / D_{d r 2} & \ldots & D_{d r 2} / D_{d r m} \\
\vdots & \vdots & \vdots & \vdots \\
D_{d r m} / D_{d r 1} & D_{d r m} / D_{d r 2} & \ldots & D_{d r m} / D_{d r m}
\end{array}\right] \\
& \boldsymbol{A}^{\left(\sigma_{s}\right)}=\left[\begin{array}{cccc}
F_{s 1} / F_{s 1} & F_{s 1} / F_{s 2} & \ldots & F_{s 1} / F_{s m} \\
F_{s 2} / F_{s 1} & F_{s 2} / F_{s 2} & \ldots & F_{s 2} / F_{s m} \\
\vdots & \vdots & \vdots & \vdots \\
F_{s m} / F_{s 1} & F_{s m} / F_{s 2} & \ldots & F_{s m} / F_{s m}
\end{array}\right]
\end{aligned}
$$

and

$$
\boldsymbol{A}^{\left(\sigma_{p}\right)}=\left[\begin{array}{cccc}
F_{p 1} / F_{s 1} & F_{p 1} / F_{p 2} & \ldots & F_{p 1} / F_{p m} \\
F_{p 2} / F_{p 1} & F_{p 2} / F_{p 2} & \ldots & F_{p 2} / \sigma_{p m} \\
\vdots & \vdots & \vdots & \vdots \\
F_{p m} / F_{p 1} & F_{p m} / F_{p m} & \ldots & F_{p m} / F_{p m}
\end{array}\right]
$$


The next step is to construct the priority vector for the matrices of Equations (10) to (14). Using Equation (5), priority vectors are defined as:

$$
\begin{aligned}
& \boldsymbol{w}^{(h)}=\left\{\frac{\prod_{1}^{m} h_{i}}{h_{1} \sum_{1}^{m} \frac{\prod_{1}^{m} h_{i}}{h_{i}}}, \frac{\prod_{1}^{m} h_{i}}{h_{2} \sum_{1}^{m} \frac{\prod_{1}^{m} h_{i}}{h_{i}}}, \ldots, \frac{\prod_{1}^{m} h_{i}}{h_{m} \sum_{1}^{m} \frac{\prod_{1}^{m} h_{i}}{h_{i}}}\right\}^{T}, \\
& \boldsymbol{w}^{\left(t_{b}\right)}=\left\{\frac{t_{b 1}}{\sum_{i=1}^{m} t_{b i}}, \frac{t_{b 2}}{\sum_{i=1}^{m} t_{b i}}, \ldots, \frac{t_{b m}}{\sum_{i=1}^{m} t_{b i}}\right\}^{T}, \\
& \boldsymbol{w}^{\left(t_{b_{\text {min }}}\right)}=\left\{\frac{t_{b_{\text {min }}}}{\sum_{i=1}^{m} t_{b_{\text {min }_{i}}}}, \frac{t_{b_{\text {min }_{2}}}}{\sum_{i=1}^{m} t_{b_{\text {min }_{i}}}}, \ldots, \frac{t_{b_{\text {minm }}}}{\sum_{i=1}^{m} t_{b_{\text {min }_{i}}}}\right\}^{T}, \\
& \boldsymbol{w}^{\left(\boldsymbol{D}_{d r}\right)}=\left\{\frac{D_{d r 1}}{\sum_{i=1}^{m} D_{d r i}}, \frac{D_{d r 2}}{\sum_{i=1}^{m} D_{d r i}}, \ldots, \frac{D_{d r n}}{\sum_{i=1}^{m} D_{d r i}}\right\}^{T}, \\
& \boldsymbol{w}^{\left(\sigma_{s}\right)}=\left\{\frac{F_{s 1}}{\sum_{i=1}^{m} F_{s i}}, \frac{F_{s 2}}{\sum_{i=1}^{m} F_{s i}}, \ldots, \frac{F_{s m}}{\sum_{i=1}^{m} F_{s i}}\right\}^{T},
\end{aligned}
$$

and

$$
\boldsymbol{w}^{\left(\sigma_{p}\right)}=\left\{\frac{F_{p 1}}{\sum_{i=1}^{m} F_{p i}}, \frac{F_{p 2}}{\sum_{i=1}^{m} F_{p i}}, \ldots, \frac{F_{p m}}{\sum_{i=1}^{m} F_{p i}}\right\}^{T} .
$$

At this step, the pair-wise comparison matrix $(A)$ for the whole hierarchy can be derived by assembling all the priority vectors (Equations (17-22)). For this purpose, each of the priority vectors forms one of the columns in the comparison matrix $(A)$ :

$$
\boldsymbol{A}=\left[\begin{array}{cccccc}
\frac{\prod_{1}^{m} h_{i}}{h_{1} \sum_{1}^{m} \frac{\prod_{1}^{m} h_{i}}{h_{i}}} & \frac{t_{b 1}}{\sum_{i=1}^{m} t_{b i}} & \frac{t_{b_{\min }}}{\sum_{i=1}^{m} t_{b_{\min }}} & \frac{D_{d r 1}}{\sum_{i=1}^{m} D_{d r i}} & \frac{F_{s 1}}{\sum_{i=1}^{m} F_{s i}} & \frac{F_{p 1}}{\sum_{i=1}^{m} F_{p i}} \\
\frac{\prod_{1}^{m} h_{i}}{h_{2} \sum_{1}^{m} \frac{\prod_{1}^{m} h_{i}}{h_{i}}} & \frac{t_{b 2}}{\sum_{i=1}^{m} t_{b i}} & \frac{t_{b_{\min }}}{\sum_{i=1}^{m} t_{b_{\min }}} & \frac{D_{d r 2}}{\sum_{i=1}^{m} D_{d r i}} & \frac{F_{s 2}}{\sum_{i=1}^{m} F_{s i}} & \frac{F_{p 2}}{\sum_{i=1}^{m} F_{p i}} \\
\vdots & \vdots & \vdots & \vdots & \vdots & \vdots \\
\frac{\prod_{1}^{m} h_{i}}{h_{n} \sum_{1}^{m} \frac{\prod_{1}^{m} h_{i}}{h_{i}}} & \frac{t_{b m}}{\sum_{i=1}^{m} t_{b i}} & \frac{t_{b_{\min } m}}{\sum_{i=1}^{m} t_{b_{m i n}}} & \frac{D_{d r m}}{\sum_{i=1}^{m} D_{d r i}} & \frac{F_{s m}}{\sum_{i=1}^{m} F_{s i}} & \frac{F_{p m}}{\sum_{i=1}^{m} F_{p i}}
\end{array}\right] .
$$

Before further progress, the consistency of the pair-wise comparison matrix $(A)$ should be checked using Equation (9).

Until now, the pair-wise comparison matrix was formed without any prioritization among the criteria. For this reason, a decision maker should prioritize each of the criteria by giving them a weight $(W)$ using Saaty's scale (Table 1). Applying the same procedure as that used for the criteria, the weight vector of the whole hierarchy is defined as:

$$
W=\left\{\frac{W_{h}}{\sum W}, \frac{W_{t_{b}}}{\sum W}, \frac{W_{t_{b_{\min }}}}{\sum W}, \frac{W_{D_{d r}}}{\sum W}, \frac{W_{F_{s}}}{\sum W}, \frac{W_{F_{p}}}{\sum W}\right\}^{T} .
$$

By multiplying $A$ to $W(A \cdot W)$, the rank of the alternatives is defined by the resultant vector.

From all of the above procedures, one can simply select the best condition of riveting following the steps of the flowchart shown in Figure 8. 


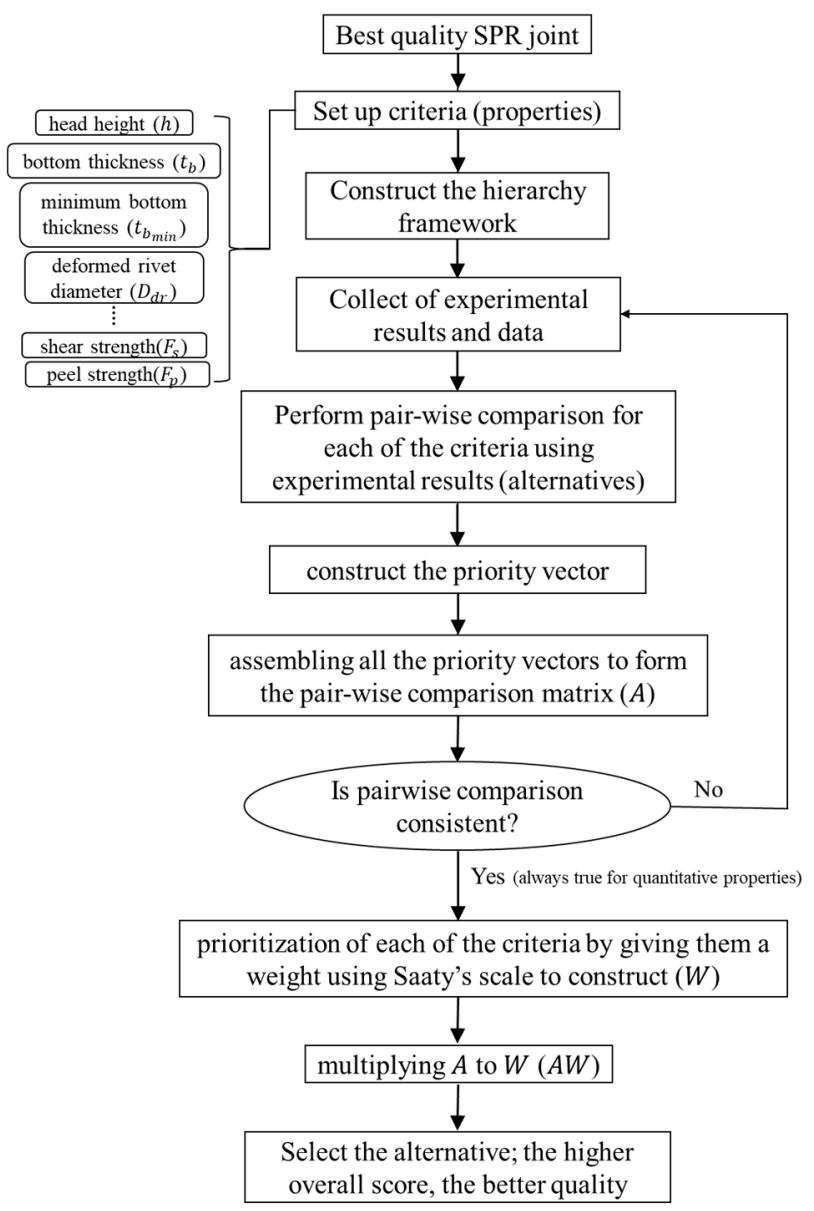

Figure 8. Flow chart to conduct analytic hierarchy process (AHP) study for SPR processing.

\subsection{Ranking the Alternatives}

Before starting the analysis for the current empirical case, it is important to consider the possibility of insertion of all of the experimental situations regardless of their quality and whether they can pass the predefined limits or not. However, to reduce the size of analysis and to decrease the number of calculations, it is better to decrease the number of alternatives by eliminating unacceptable conditions, considering the point that the low quality conditions spontaneously will be placed at the end of the ranking by AHP. Therefore, eliminating the poor conditions does not have any effect on the final assessment. Inserting data in Table 4 into Matrix (A) (Equation (23)), the comparison matrix is defined as:

$$
A=\left[\begin{array}{llllll}
0.179 & 0.146 & 0.151 & 0.142 & 0.128 & 0.145 \\
0.089 & 0.137 & 0.140 & 0.153 & 0.131 & 0.147 \\
0.149 & 0.157 & 0.149 & 0.148 & 0.139 & 0.149 \\
0.081 & 0.178 & 0.169 & 0.144 & 0.126 & 0.130 \\
0.224 & 0.113 & 0.117 & 0.142 & 0.163 & 0.146 \\
0.149 & 0.132 & 0.132 & 0.137 & 0.162 & 0.143 \\
0.128 & 0.136 & 0.140 & 0.133 & 0.151 & 0.138
\end{array}\right]
$$

Using Equation (8), with inconsistency issues in consideration, GCI is calculated as zero $(<0.370)$, which means that the comparisons are completely consistent. This is reasonable, since all of the presented data in the current work are quantitative.

Furthermore, in this step, it is necessary to rank the criteria based on Table 1, which means the pair-wise comparison of the criteria. It is the decision maker's responsibility to verbally judge between the criteria based on their knowledge, scientific or industrial requirements and standards, and the 
customer's demand. The selected Saaty's scale is summarized in Table 5. The scales in Table 1 are used when $i$ has an equal or higher importance in comparison to $j$. This means that if the weight of $i$ over $j$ is $x$ according to Saaty's scale, then the weight of $j$ over $i$ is simply $1 / x$, which could not be found in Table 1. The most important parameter in performance assessment of a joint is its strength. Therefore, the highest relative importance numbers are associated with shear and peel strength over others. However, the relative importance of shear and peel strengths were assumed to be the same, although in real applications they may have different importance. The second important parameter is the head height and minimum bottom thickness. There are strict rules and standards on head height in different applications, especially in the automobile industry. Hence, giving a high priority to head height is meaningful. Also, the minimum bottom thickness is crucial because of its role in the failing of a joint. Although the importance of the bottom thickness is lower than that of head height/minimum bottom thickness, it is more important than deformed rivet diameter. As long as the rivet is stable (do not lose its strength or fail), a higher deformed rivet diameter can provide a stronger interlock.

Table 5. Relative importance of the criteria.

\begin{tabular}{ccccccc}
\hline Parameters & $\begin{array}{c}\text { Head } \\
\text { Height }\end{array}$ & $\begin{array}{c}\text { Bottom } \\
\text { Thickness }\end{array}$ & $\begin{array}{c}\text { Minimum } \\
\text { Bottom } \\
\text { Thickness }\end{array}$ & $\begin{array}{c}\text { Deformed } \\
\text { Rivet } \\
\text { Diameter }\end{array}$ & $\begin{array}{c}\text { Shear } \\
\text { Strength }\end{array}$ & $\begin{array}{c}\text { Peel } \\
\text { Strength }\end{array}$ \\
\hline Head height & 1 & 2 & 1 & 3 & 0.5 & 0.5 \\
\hline Bottom thickness & 0.5 & 1 & 0.5 & 2 & 0.33 & 0.33 \\
\hline $\begin{array}{c}\text { Minimum bottom } \\
\text { thickness }\end{array}$ & 1 & 2 & 1 & 3 & 0.5 & 0.5 \\
\hline $\begin{array}{c}\text { Deformed rivet } \\
\text { diameter }\end{array}$ & 0.33 & 0.5 & 0.33 & 1 & 0.25 & 0.25 \\
\hline Shear strength & 2 & 3 & 0.5 & 4 & 1 & 1 \\
\hline Peel strength & 2 & 3 & 0.5 & 4 & 1 & 1 \\
\hline
\end{tabular}

Using scales in Table 5 and Equation (24), the weight vector of the whole hierarchy is calculated as:

$$
W=\{0.153,0.088,0.154,0.55,0.274,0.274\}^{T} .
$$

By multiplying Equation (25) with Equation (26), final priorities of the alternatives is obtained. The final priorities and rank of the joints are presented in Table 6.

Table 6. Rank of joints (alternatives) and their priorities.

\begin{tabular}{ccc}
\hline Rank & Final Priorities & Joint \\
\hline 1 & 0.155 & $J_{5}$ \\
2 & 0.147 & $J_{3}$ \\
3 & 0.146 & $J_{6}$ and $J_{1}$ \\
4 & 0.140 & $J_{7}$ \\
5 & 0.133 & $J_{4}$ \\
6 & 0.132 & $J_{2}$ \\
\hline
\end{tabular}

$J_{5}$ is ranked as first. Considering the properties of this joint in Table 4, it is evident that the highest shear strength and the lowest head height correspond to this joint. Its peel strength is the same as that of $J_{1}$, which is placed third in Table 6 . The second rank in Table 6 is occupied by $J_{3}$, which has the highest peel strength. Also, it has a higher deformed rivet diameter and lower bottom and minimum bottom thicknesses in comparison to $J_{5}$. Paying attention to the condition of the joints in Table 3 , it is interesting to see that for the rivets with a hardness of $460 \mathrm{Hv}$, the best joint was achieved by applying a velocity of $350 \mathrm{~mm} / \mathrm{s}$. On the other hand, for the rivets with a lower hardness of $440 \mathrm{Hv}$, the performance of 
the joint is the best at a higher velocity of $360 \mathrm{~mm} / \mathrm{s}$. This contradicts a pre-assumption that using the lower hardness rivets and keeping all other parameters unchanged, a joint with the same performance can be achieved with a lower force. This is a simple example to declare the importance of AHP in multi-criteria problems in materials science, such as SPR joints.

Figure 9 shows the microstructure changes in different areas of the best quality joint $\left(J_{5}\right)$. As seen in Figure 9a, the microstructure of the as-received sheet consists of almost equi-axed grains, with an average grain size of $45 \mu \mathrm{m}$. In the area near the rivet's tip grain refinement happens (see Figure $9 \mathrm{~b}$ ) as a result of the deformation that happens in this area and the compressive stress applied by the insertion of the rivet. Also, the grains are elongated as a result of the material flow. The average grain size in this area is approximately $40 \mu \mathrm{m}$. By approaching the rivet's tail, grains become more elongated and the grain refinement increases. The approximate grain size of the grains in this region (Figure 9c) is $25 \mu \mathrm{m}$. This means the decrease in the grain size by $38 \%$ is noteworthy. As seen in Figure $9 \mathrm{~d}$, the microstructure around the joint is more equi-axed in comparison to the other regions and the microstructure is more similar to the as-received one, with an average grain size of $36 \mu \mathrm{m}$.

Another stimulating result of the analysis is $J_{1}$. It is ranked third, however this joint is standing higher than $J_{7}, J_{4}$, and $J_{2}$, despite its lower shear strength. This confirms that it is not correct to select the condition of the best joint based on only one parameter, even though that parameter is the most important one (shear strength) among the others. Also, this shows that by lowering the die depth, longer rivets with lower hardness are required for an acceptable joint.

Finally, it is possible to insert other criteria into this analysis, depending on decision makers' requirements. Also, it is possible to use qualitative criteria, such as the appearance of surface cracks and deflection of the sheet, in the mentioned model. The point is that in this case, a consistency check will be an important step and can be used either for the pair-wise comparison matrixes of each criterion, or the total pair-wise comparison matrix.

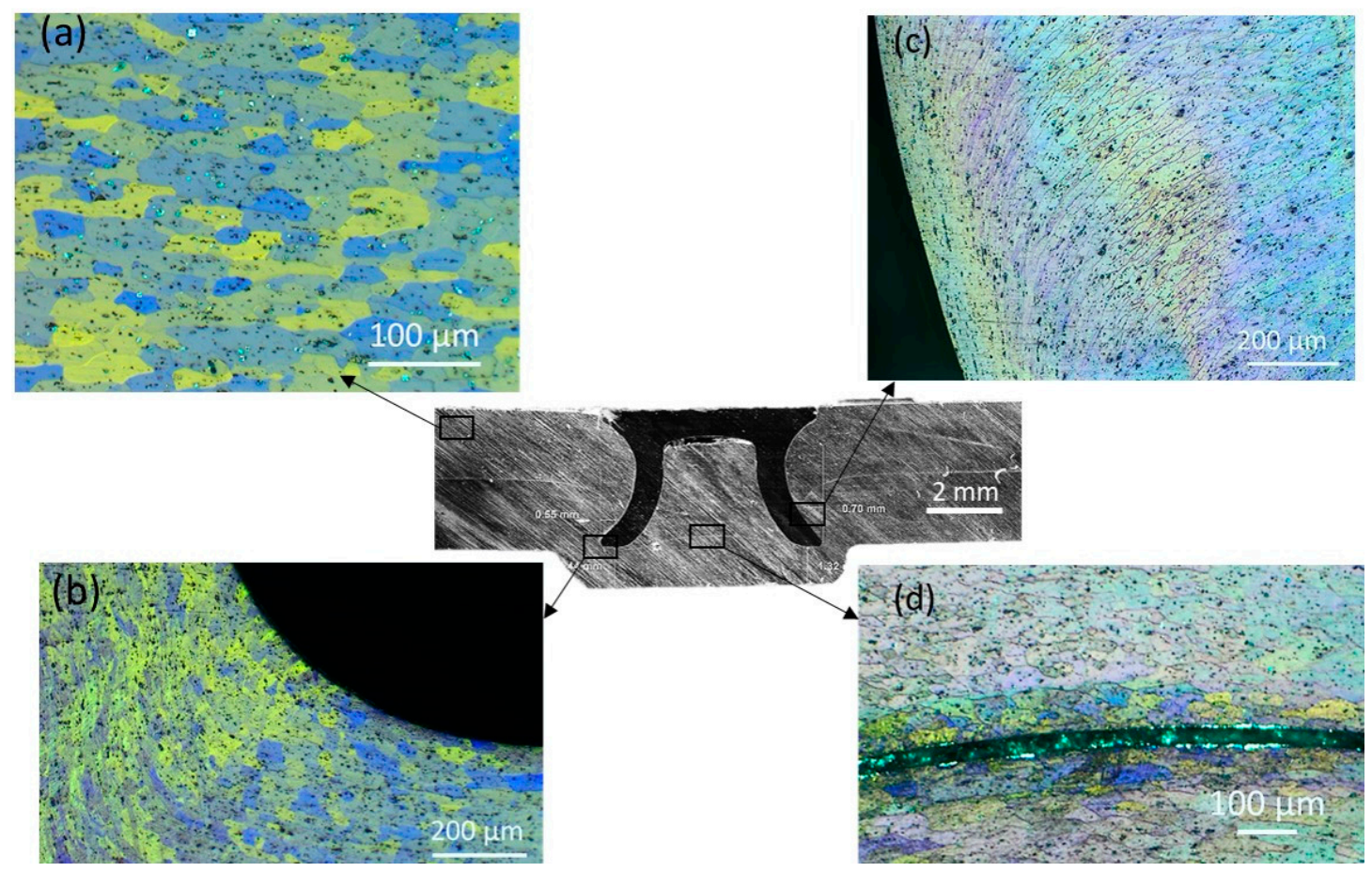

Figure 9. Microstructure of the joint in different areas: (a) far from the joint (as-received sheet); (b) around rivets tip; (c) near the rivet's wall; (d) the joint. 


\section{Summary}

The aim of this work is to select a joint having the best combination of interlocking and strength among the approved SPR joints. The Analytic Hierarchy Process (AHP) was used as the multi-criteria decision-making method. A general AHP model, which can be used in different conditions and with unlimited number of criteria and alternatives, was proposed. As a practical example, SPR experiments were carried out using AA6082 aluminium sheets in T6 condition with a thickness of $2.5 \mathrm{~mm}$. A number of parameters, such as die shape and geometry, rivet shape and hardness, and the riveting velocity (force), were tested to achieve acceptable joints. Using cross-sectional investigation and strength tests, seven SPR joints were selected among a large amount of joints, despite the fact that it is possible to insert all of the empirical cases into the analysis. Four criteria were nominated to evaluate the interlocking, including head height, bottom thickness, minimum bottom thickness, and deformed rivet diameter. Additionally, two criteria, namely shear strength and peel strength, were selected for strength assessment. Findings from the AHP method showed that the best combination of the strength and interlocking conditions for the joining of AA6082 aluminium sheets in T6 condition with a thickness of $2.5 \mathrm{~mm}$ was achieved by using a die with a diameter of $10 \mathrm{~mm}$ and depth of $1.4 \mathrm{~mm}$ and a rivet with a length of $6.5 \mathrm{~mm}$ and a hardness of $4.6 \mathrm{Hv}$ with a velocity of $350 \mathrm{~mm} / \mathrm{s}$. The AHP analysis also showed that by lowering the die depth, longer rivets with lower hardness are required for an acceptable joint. Furthermore, AHP modelling results suggested that selecting joints without considering all of the involved parameters could result in a wrong decision and the selection of the best condition using the most important parameter(s) may lead to a misjudgment.

Author Contributions: E.B. designed and conducted the experiments, proposed the model, analysed the data, and wrote the original draft. Y.H. designed the experiments, supervised the research, and revised the final manuscript. Z.F. funded the project and revised the final manuscript.

Funding: This work was carried out as a part of research studies within a collaborative research project entitled Rapid Aluminium Cost Effective Forming (RACEFORM) that was funded by Advanced Propulsion Centre UK, Ltd. through the Innovate UK.

Acknowledgments: Ebad Bagherpour appreciates the support of BCAST, Brunel University London, for the use of SPR facilities at the Advanced Metal Processing Centre (AMPC).

Conflicts of Interest: The authors declare no conflict of interest.

\section{References}

1. Cacko, R. Review of different material separation criteria in numerical modeling of the self-piercing riveting process-SPR. Arch. Civ. Mech. Eng. 2008, 8, 21-30. [CrossRef]

2. Haque, R. Quality of self-piercing riveting (SPR) joints from cross-sectional perspective: A review. Arch. Civ. Mech. Eng. 2018, 18, 83-93. [CrossRef]

3. Li, D.; Chrysanthou, A.; Patel, I.; Williams, G. Self-piercing riveting-A review. Int. J. Adv. Manuf. Technol. 2017, 92, 1777-1824. [CrossRef]

4. Abe, Y.; Kato, T.; Mori, K. Self-piercing riveting of high tensile strength steel and aluminium alloy sheets using conventional rivet and die. J. Mater. Process. Technol. 2009, 209, 3914-3922. [CrossRef]

5. de Rijck, J.J.M.; Homan, J.J.; Schijve, J.; Benedictus, R. The driven rivet head dimensions as an indication of the fatigue performance of aircraft lap joints. Int. J. Fatigue 2007, 29, 2208-2218. [CrossRef]

6. Han, L.; Chrysanthou, A. Evaluation of quality and behaviour of self-piercing riveted aluminium to high strength low alloy sheets with different surface coatings. Mater. Des. 2008, 29, 458-468. [CrossRef]

7. Ashby, M.F.; Bréchet, Y.J.M.; Cebon, D.; Salvo, L. Selection strategies for materials and processes. Mater. Des. 2004, 25, 51-67. [CrossRef]

8. Chiner, M. Planning of expert systems for materials selection. Mater. Des. 1988, 9, 195-203. [CrossRef]

9. Jahan, A.; Edwards, K.L.; Bahraminasab, M. 4-Multi-criteria decision-making for materials selection. In Multi-Criteria Decision Analysis for Supporting the Selection of Engineering Materials in Product Design, 2nd ed.; Jahan, A., Edwards, K.L., Bahraminasab, M., Eds.; Butterworth-Heinemann: Oxford, UK, 2016; pp. 63-80. 
10. Zafarani, H.; Hassani, A.; Bagherpour, E. Achieving a desirable combination of strength and workability in $\mathrm{Al} / \mathrm{SiC}$ composites by AHP selection method. J. Alloys Compd. 2014, 589, 295-300. [CrossRef]

11. Saaty, T.L. How to make a decision: The analytic hierarchy process. Eur. J. Oper. Res. 1990, 48, 9-26. [CrossRef]

12. Brunelli, M. Introduction to the Analytic Hierarchy Process, 1st ed.; Springer: New York, NY, USA, 2015.

13. Mansor, M.R.; Sapuan, S.M.; Zainudin, E.S.; Nuraini, A.A.; Hambali, A. Hybrid natural and glass fibers reinforced polymer composites material selection using Analytical Hierarchy Process for automotive brake lever design. Mater. Des. 2013, 51, 484-492. [CrossRef]

14. Kiong, S.C.; Lee, L.Y.; Chong, S.H.; Azlan, M.A.; Nor, M.; Hisyamudin, N. Decision making with the analytical hierarchy process (AHP) for material selection in screw manufacturing for minimizing environmental impacts. Appl. Mech. Mater. 2013, 315, 57-62. [CrossRef]

15. Di Angelo, L.; Di Stefano, P.; Fratocchi, L.; Marzola, A. An AHP-based method for choosing the best 3D scanner for cultural heritage applications. J. Cult. Herit. 2018, 34, 109-115. [CrossRef]

16. Khorshidi, R.; Hassani, A.; Rauof, A.H.; Emamy, M. Selection of an optimal refinement condition to achieve maximum tensile properties of $\mathrm{Al}-15 \% \mathrm{Mg}_{2} \mathrm{Si}$ composite based on TOPSIS method. Mater. Des. 2013, 46, 442-450. [CrossRef]

17. Ishizaka, A.; Labib, A. Review of the main developments in the analytic hierarchy process. Expert Syst. Appl. 2011, 38, 14336-14345. [CrossRef]

18. Saaty, T.L. Fundamentals of Decision Making, 1st ed.; RWS Publications: Pittsburgh, PA, USA, 1994.

19. Dweiri, F.; Al-Oqla, F.M. Material selection using analytical hierarchy process. Int. J. Comput. Appl. Technol. 2016, 26, 182-189. [CrossRef]

20. Perez-Vega, S.; Peter, S.; Salmeron-Ochoa, I.; Nieva-de la Hidalga, A.; Sharratt, P.N. Analytical hierarchy processes (AHP) for the selection of solvents in early stages of pharmaceutical process development. Process Saf. Environ. 2011, 89, 261-267. [CrossRef]

21. Crawford, G.; Williams, C. A note on the analysis of subjective judgment matrices. J. Math. Psychol. 1985, 29, 387-405. [CrossRef]

22. Saaty, T.L. A scaling method for priorities in hierarchical structures. Math. Psychol. 1977, 15, $234-281$. [CrossRef]

23. Peláez, J.I.; Lamata, M.T. A new measure of consistency for positive reciprocal matrices. Comput. Math. Appl. 2003, 46, 1839-1845. [CrossRef]

24. Kwiesielewicz, M.; van Uden, E. Inconsistent and contradictory judgements in pairwise comparison method in the AHP. Comput. Oper. Res. 2004, 31, 713-719. [CrossRef]

25. Karapetrovic, S.; Rosenbloom, E.S. A quality control approach to consistency paradoxes in AHP. Eur. J. Oper. Res. 1999, 119, 704-718. [CrossRef]

26. Aguaron, J.; Moreno-Jiménez, J.M. The geometric consistency index: Approximated thresholds. Eur. J. Oper. Res. 2003, 147, 137-145. [CrossRef]

(C) 2019 by the authors. Licensee MDPI, Basel, Switzerland. This article is an open access article distributed under the terms and conditions of the Creative Commons Attribution (CC BY) license (http://creativecommons.org/licenses/by/4.0/). 